\title{
An Analysis Educational Guidelines of Mathematics Education Provision for Primary School from High Score Countries on Timss 2015
}

\author{
Ruangdech Sirikit ${ }^{1, *}$, Panwasn Mahalawalert ${ }^{1}$, Vetcharit Angganapattarakajorn ${ }^{2}$ \\ ${ }^{1}$ Educational and Psychological Test Bureau, Srinakharinwirot University, Bangkok, Thailand \\ ${ }^{2}$ Faculty of Education, Burapha University, Thailand
}

Received July 4, 2020; Revised November 2, 2020; Accepted November 11, 2020

\section{Cite This Paper in the following Citation Styles}

(a): [1] Ruangdech Sirikit, Panwasn Mahalawalert, Vetcharit Angganapattarakajorn , "An Analysis Educational Guidelines of Mathematics Education Provision for Primary School from High Score Countries on Timss 2015," Universal Journal of Educational Research, Vol. 8, No. 12A, pp. 7227 - 7232, 2020. DOI: 10.13189/ujer.2020.082504.

(b): Ruangdech Sirikit, Panwasn Mahalawalert, Vetcharit Angganapattarakajorn (2020). An Analysis Educational Guidelines of Mathematics Education Provision for Primary School from High Score Countries on Timss 2015. Universal Journal of Educational Research, 8(12A), 7227- 7232. DOI: 10.13189/ujer.2020.082504.

Copyright $₫ 2020$ by authors, all rights reserved. Authors agree that this article remains permanently open access under the terms of the Creative Commons Attribution License 4.0 International License

Abstract The objectives of this research were 1) to study effects of student characteristic variables and educational institution characteristic variables on the quality assessment of mathematics study management at primary school of countries achieving high test scores, i.e. Singapore, South Korea, and the Hong Kong Special Administrative Region and 2) to compare similarities and differences of student characteristic variables and educational institution characteristic variables on the quality assessment of mathematics study management in Singapore, South Korea, and the Hong Kong Special Administrative Region. The data used in this research are secondary data from the 2015 Trends in International Mathematics and Science Study (TIMSS). The data were collected from 4,669 students across 100 schools in the Republic of Korea, 6,517 students across 100 schools in Singapore and 3,600 students across 100 schools in Hong Kong. The three steps taken for data analysis are as follows - 1) To analyze descriptive statistics 2) To estimate the ability of students from the assessment of their mathematics proficiency using IRTPRO program; 3) To analyze variables affecting student and school with Hierarchical Linear Modeling (HLM) and two levels of analysis. The findings from the study revealed that 1 . The proportion of all variances explained for variables or coefficient of prediction $\left(\mathrm{R}^{2}\right)$ indicated Singapore's coefficient of prediction at a student level was 0.2750 $(27.50 \%)$ and at a school level was 0.7250 (72.50\%).
Republic of Korea's coefficient of prediction at a student level was $0.2183(21.83 \%)$ and at an school level was 0.6288 (62.88\%), the Hong Kong Special Administrative Region's coefficient of prediction at a student level was $0.1477(14.77 \%)$ and at a school level was 0.4482 (44.82\%). 2. Multi-level analysis of student-level variables found that 7 variables affecting the quality of mathematics study management. Namely, 3 countries had 2 variables, 2 countries had 4 variables, and 1 country had 1 variable. As for multi-level analysis of educational-level variables, it was found that 5 variables affecting the quality of mathematics study management. Namely, 2 countries had 1 variable and 1 country had 4 variables.

Keywords Mathematics, TIMSS 2015

\section{Introduction}

Value-added model is a method that helps report results reflecting information about educational management whether or not educational institutions create value-added to learning outcomes more or less by comparing scores from actual learning outcomes or observed scores to predictable learning outcomes (predicted scores) based on student background variables, community context 
variables, social variables or variables associated with existing achievement (Sirichai Kanchanawasi, 2007) [1], [2]. The use of value-added model in education is gathering statistical techniques with the use of student test scores to estimate the effect size of educational institutions or teachers (MaCaffrey, Lockwood, Koretz, \& Hamilton, 2003) [3]. There are two ways for using the value-added model. The first one is assessing responsibility in educational institutions that can be auditable and the second one is assessing the relative effectiveness of teachers. Some models consider only students' existing knowledge or take other variables such as sex, religion, and economic status into consideration [4], [5], [6], [7]. The TIMSS 2015 assessment results reported Singapore achieved the highest mean score in mathematics (621 points), followed by South Korea (the average score of 606) while Thailand had the average score of 431 which was listed in a low-level group [8]. Therefore, the researcher was interested in assessing the quality of educational management of the country members and analyzing mathematics study management guidelines for basic education of countries achieving high test scores from Trends in International Mathematics and Science Study with the application of value-added analysis and analysis of differential item functioning in tests. Data in the study were employed from the 2015 Trends in International Mathematics and Science Study (TIMSS) conducted by The International Association for the Evaluation of Educational Achievement (IEA) and Singapore scored the highest on the TIMSS, followed by Hong Kong respectively.

\section{Aim}

1. To study effects of student characteristic variables and educational institution characteristic variables on the quality assessment of mathematics study management at primary school of countries achieving a high level of test scores, i.e. Singapore, South Korea, and the Hong Kong Special Administrative Region.

2. To compare similarities and differences of student characteristic variables and educational institution characteristic variables on the quality assessment of mathematics study management in Singapore, South Korea, and the Hong Kong Special Administrative Region.

\section{Definitions}

Efficiency of quality assessment means coefficient of determination $\left(\mathrm{R}^{2}\right)$ from the model of quality assessment, which is the multi-level analysis model with factor control in the level of students and educational institutions affecting the learning of students.

TIMSS 2015 is the internationally comparative assessment dedicated to improving teaching and learning in mathematics and science for students around the world. TIMSS 2015 uses the broadly defined curriculum as the major organizing concept in considering how educational opportunities are provided to students and the factors that influence how students use these opportunities. Test items were designed to measure the breadth of content in number, geometric shapes and measures and data display. TIMSS 2015 included an extensive test development effort to support the mathematics assessment framework. At the fourth grade, the test includes 179 items and approximately half the items are constructed responses while the other half are multiple choice.

\section{Methods}

The research was conducted and divided into 3 parts as Part 1: Data used in the study; Part 2: Details of data collection; Part 3: Data analysis. Details are shown below:

\section{Part 1: Data used in the study}

\section{1) Samples for Study}

The study employed secondary data of the 2015 Trends in International Mathematics and Science Study (TIMSS 2015). The sample participating in the study for data collection were students, teachers of mathematics who teach students being the sample in this study, and administrators of educational institutions where the students were learning as seen in Table 1

Table 1. Number of samples for assessment by country

\begin{tabular}{ccc}
\hline Country & School Number & Student Number \\
\hline Singapore & 100 & 6,517 \\
\hline Hong Kong & 100 & 3,600 \\
\hline Republic of Korea & 100 & 4,669 \\
\hline
\end{tabular}

\section{Part 2: Details of data collection}

Test - TIMSS 2015 assessment test contained 179 items in mathematics, considered to be many items. To enable students to complete all items within the specified response time, 1 hour 30 minutes (the amount of time spent on each subject was 45 minutes), each subject test was divided into 14 booklets consisting of multiple-choice items and constructed-response items. The tests were made of content and curricula from countries participating in the TIMSS 2015. Each cluster of the items had a proportion of subject content and learning behavior according to the TIMSS assessment framework of mathematics achievement. To collect data for the assessment, the assessment involved assembling the items into 14 blocks and each block contained 23-29 mathematics items. TIMSS provides a standard for systematic random assessment tests with a very careful rotated design. Therefore, students with seating arrangement next to each other will not have a 
chance to be given the same test booklet and everyone shall start doing the test of each part at the same time.

Student questionnaire: All students being participants in the study were required to respond to a questionnaire after they finished the test. Students completed the 30-minute questionnaire designed to provide information about their general information, studying mathematics in their educational institutions, using computers for studying mathematics and other, their educational institutions, activities they do outside their educational institutions, and doing mathematics homework.

Educational institution questionnaire: An administrator whose students were the study participants was required to respond to a questionnaire designed to provide characteristics of the educational institution, school operation as being an administrator, parents' participation in school activities, learning atmosphere in school, mathematics study management in school, students' behaviors, and sources of learning and technologies.

\section{Part 3: Data Analysis}

This research had three steps of analysis as follows:

Step 1 To analyze descriptive statistics

The analysis of basic statistic values of data was conducted for analyzing fundamental data by means of descriptive statistics, i.e., the frequency, percentage, mean, standard deviation, highest value, and lowest value.

Step 2 To estimate students' ability

To estimate the ability of students from the assessment of their mathematics proficiency using the IRTPRO program.

Step 3 To analyze affecting variables

To analyze the variables affecting the student and school with Hierarchical Linear Modeling (HLM) and two levels of analysis and comparing the similarity and difference of characteristic variables of students and schools toward the quality assessment of the mathematics subject. Competency in describing variance of dependent variables with predictor variable or coefficient of determination $\left(\mathrm{R}^{2}\right)$ in each model had the following equation [3], [9], [10]:

Variance of residual value reduced when with predictor variable

Variance of residual value reduced when without predictor variable

\section{Results}

The results of variables affecting on a quality assessment of learning mathematics were concluded as follows:

\section{Singapore}

Effects of student characteristic variables and educational institution characteristic variables on the quality assessment of mathematics study management at primary school of countries achieving high test scores, i.e. Singapore, Republic of Korea, and the Hong Kong Special Administrative Region are detailed below:

\section{Singapore}

Multi-level analysis in Singapore based on fixed effect tests found that the mean students' abilities from mathematics skill assessment in all educational institutions (G00) had no variation from zero (G00 = -0.0009), the regression coefficient of educational institution variables having the maximum positive value was policies supporting academic achievement in educational institutions ( $\beta=0.0390$ ). This is to say that educational institutions providing policies to support academic achievement will have increased students' abilities from assessment skills on mathematics. The student-level variable having the most positive influence was confidence in learning mathematics ( $\beta=0.1859$ ).

Random effect test results found that the educational institution-level remainder of students' abilities from mathematics skill assessment with controlled student-level and educational institution-level variables (U0) or value-added of educational institutions had variation among educational institutions with a statistical significance level of $0.01\left(\chi^{2}=733.91281\right)$. The variation among educational institutions was 0.0449 which variance could be described by $8.30 \%$ and variation within educational institutions was 0.4959 which variance could be described by $91.70 \%$.

\section{Republic of Korea}

Multi-level analysis in Republic of Korea (South Korea) based on fixed effect tests indicated that the mean students' abilities from mathematics skill assessment in all educational institutions (G00) had no variation from zero ( $G 00=-0.0221$ ), the regression coefficient of educational institution variables having the maximum positive value was recruiting students to schools based on mathematical calculation skills ( $\beta=0.0720$ ). This is to say that educational institutions recruiting students based on mathematical calculation skills will have increased students' abilities from assessment skills on mathematics. The student-level variable having the most positive influence was confidence in learning mathematics $(\beta=$ 0.2617).

Random effect test results found that the educational institution-level remainder of students' abilities from mathematics skill assessment with controlled student-level and educational institution-level variables (U0) or value-added of educational institutions had variation among educational institutions with a statistical significance level of 0.01 ( $\left.\chi^{2}=378.38310\right)$. The variation among educational institutions was 0.0312 which variance could be described by $5.16 \%$ and variation within educational institutions was 0.5734 which variance could be described by $94.83 \%$. 


\section{The Hong Kong Special Administrative Region}

Multi-level analysis in the Hong Kong Special Administrative Region based on fixed effect tests indicated that the mean students' abilities from mathematics skill assessment in all educational institutions (G00) had no variation from zero ( $\mathrm{G} 00=$ 0.0069), the regression coefficient of educational institution variables having the maximum positive value was a low level of discipline problems among students ( $\beta=0.0499$ ). This is to say that educational institutions having a low level of discipline problems among students will have increased students' abilities from assessment skills on mathematics. The student-level variable having the most positive influence was confidence in learning mathematics ( $\beta=0.1502)$.

Random effect test results found that the educational institution-level remainder of students' abilities from mathematics skill assessment with controlled student-level and educational institution-level variables (U0) or value-added of educational institutions had variation among educational institutions with a statistical significance level of $0.01\left(\chi^{2}=695.01457\right)$. The variation among educational institutions was 0.0955 which variance could be described by $15.02 \%$ and variation within educational institutions was 0.5405 which variance could be described by $84.98 \%$.

Proportion of all variances of variables that can be described or coefficient of prediction $\left(R^{2}\right)$ indicated Singapore's coefficient of prediction at a student level was $0.2750(27.50 \%)$ and at an educational institution level was $0.7250(72.50 \%)$.

Republic of Korea's coefficient of prediction at a student level was $0.2183(21.83 \%)$ and at an educational institution level was 0.6288 (62.88\%).

The Hong Kong Special Administrative Region's coefficient of prediction at a student level was 0.1477 (14.77\%) and at an educational institution level was 0.4482 (44.82\%).

Table 2. Summary of Variance of Explained Dependent Variables

\begin{tabular}{|c|c|c|c|}
\hline Variables & Singapore & Korea & Hong Kong \\
\hline Mean of students' ability & -.0009 & -.0221 & .0069 \\
\hline \multicolumn{4}{|l|}{ Student level } \\
\hline 1. Sex & $-.0783^{* *}$ & .0147 & .0017 \\
\hline 2. Feeling of being a part of school & .0006 & $.0187^{* *}$ & $.0197^{* *}$ \\
\hline 3. Being bullied by friends at school & $.0300^{* *}$ & $-.0317 * *$ & .0071 \\
\hline 4. Feeling of liking learning mathematics & -.0088 & .0095 & -.0070 \\
\hline 5. Good attitude towards teachers of mathematics & $-.0205^{* *}$ & $-.0477 * *$ & -.0157 \\
\hline 6. Confidence in learning mathematics & $.1859 * *$ & $.2617^{* *}$ & $.1502^{* *}$ \\
\hline 7. Learning resources at students' homes & $.1525^{* *}$ & $.0900^{* *}$ & $.0714^{* *}$ \\
\hline 8. Support of learning outside the classroom. & $-.0405^{*}$ & $.0976 * *$ & -.0221 \\
\hline \multicolumn{4}{|l|}{ Educational institution level } \\
\hline 1. Support of instructional media & -.0104 & $-.0171^{*}$ & .0129 \\
\hline 2. Policies supporting academic achievement & $.0390 * *$ & .0148 & .0272 \\
\hline $\begin{array}{l}\text { 3. A low level of discipline problems among } \\
\text { students }\end{array}$ & .0008 & .0102 & $.0499 *$ \\
\hline $\begin{array}{l}\text { 4. Recruiting students to schools based on } \\
\text { mathematical calculation skills. }\end{array}$ & -.0188 & $.0720 * *$ & -.0361 \\
\hline 5. Students' level of preparedness & $-.0677^{*}$ & $-.1278 * *$ & -.0796 \\
\hline $\begin{array}{l}\text { 6. Number of teaching and learning hours per } \\
\text { academic year }\end{array}$ & .0002 & -.0001 & -.0004 \\
\hline \multicolumn{4}{|l|}{ variance components } \\
\hline Level 1: Variance within educational institutions (R) & .4959 & .5734 & .5405 \\
\hline $\begin{array}{llll}\begin{array}{l}\text { Level } \\
\text { institutions(U0). }\end{array} & \text { Variance } & \text { among } & \text { educational } \\
\end{array}$ & .0449 & .0312 & .0955 \\
\hline \multicolumn{4}{|c|}{ Variance level of students' competency from mathematics proficiency evaluation at } \\
\hline within educational institution (Level 1) & $\begin{array}{c}.9170 \\
(91.70 \%) \\
\end{array}$ & $\begin{array}{c}.9483 \\
(94.83 \%) \\
\end{array}$ & $\begin{array}{c}.8498 \\
(84.98 \%) \\
\end{array}$ \\
\hline between educational institution (Level 2) & $\begin{array}{c}.0830 \\
(8.30 \%)\end{array}$ & $\begin{array}{c}.0516 \\
(5.16 \%) \\
\end{array}$ & $\begin{array}{c}.1502 \\
(15.02 \%) \\
\end{array}$ \\
\hline \multicolumn{4}{|c|}{ Proportion of all variance of explained dependent variables $\left(\mathrm{R}^{2}\right)$} \\
\hline Level 1 & $\begin{array}{c}.2750 \\
(27.50 \%)\end{array}$ & $\begin{array}{c}.2183 \\
(21.83 \%)\end{array}$ & $\begin{array}{c}.1477 \\
(14.77 \%)\end{array}$ \\
\hline Level 2 & $\begin{array}{c}.7250 \\
(72.50 \%)\end{array}$ & $\begin{array}{c}.6288 \\
(62.88 \%)\end{array}$ & $\begin{array}{c}.4482 \\
(44.82 \%)\end{array}$ \\
\hline
\end{tabular}




\section{Discussion}

The research results revealed that there were various variables having influence on changes in mathematics assessment test scores of Republic of Korea, Singapore, and the Hong Kong Special Administrative Region with regard to the student- level such as sex, feeling of being a part of school, being bullied by friends at school, positive attitude towards teachers of mathematics, confidence in learning mathematics, learning resources at students' homes, and support of learning outside the classroom, and with regard to the educational institution-level such as support of instructional media, policies supporting academic achievement, a low level of discipline problems among students, recruiting students to schools based on mathematical calculation skills, and students' level of preparedness [11], [12]. It can be seen that characteristics of student-level and educational institution-level variables had effects on the quality assessment of educational management, having consistency with real situations. The quality of educational institutions in many countries is highly different. One of various reasons is difference in significant resources such as finance, personnel or sizes of educational institutions. Such differences appear to be value-added different in each educational institution.

With regard to the comparison of similarities and differences of student characteristic variables and educational institutions towards the quality assessment of mathematics study management among Republic of Korea, Singapore, and the Hong Kong Special Administrative Region, the quality assessment of educational management using value-added analysis for maximum efficiency, it is necessary to take details of student-level variables into consideration so as to increase reliability of the obtain assessment results as well [13], [14].

\section{Suggestions}

\section{Suggestion for application of research}

This research was conducted to study variables of Republic of Korea, Singapore, and the Hong Kong Special Administrative Region being the countries achieving a high level of TIMSS2015 assessment test scores. Therefore, educational institutions can apply both student-level and educational institution-level variables affecting the quality of educational management to develop their students for having more achievement of mathematic study.

\section{Suggestion for future research}

The data used in the research were secondary obtained from Trends in International Mathematics and Science Study in 2015 or TIMSS 2015. Some restrictions that the researcher found were student-level and educational institution-level variables. As the data were collected, some interesting variables from studying relevant documents and research studies were not included in the database. For future research, a researcher should administer a self-collection of data. A researcher probably prepares a test and synthesizes variables to really meet the context of Thailand so as to create additional value to a research study increasingly.

\section{Acknowledgment}

The author is very grateful to Srinakharinwirot University (www.swu.ac.th) for encouragement and supporting.

\section{REFERENCES}

[1] Sirichai Kanchanawasi. (2007). Multi-level analysis. The 4th edition. Bangkok: Chulalongkorn University Press.

[2] Anong Intaprom (2009). A Multilevel Analysis of Teacher-Level and Student-Level Factors Effecting on Students' Mathematics Achievement. Doctoral Thesis, Department of Educational Research and Psychology, Faculty of Education, Chulalongkorn University.

[3] McCaffrey, D. F., Koretz, D. M., Lockwood, J. R., \& Hamilton, L. S. (2004). The promise and peril of using value-added modeling to measure teacher effectiveness (Research Brief No. RB-9050-EDU). Santa Monica, CA: RAND Corporation. Retrieved February 19, 2009, from http://www.rand.org/pubs/research_briefs/2005/RAND_RB 9050.pdf

[4] Prakittiya Tuksino. (2009). A Quality assessment of science instructional management in basic education schools: an application of differential item functioning and value-added model. Doctor of Philosophy Dissertation, Department of Educational Research and Psychology, Graduate School Chulalongkorn University.

[5] Ruangdech Sirikit. (2012). A comparative analysis of the model of a quality assessment of mathematics subject: an application of differential item functioning and differential distractor functioning. Doctoral Thesis, Department of Educational Research and Psychology, Graduate School, Chulalongkorn University.

[6] Boonrueng Sriharun (2009). A Study of Educational Factors Relating to and Influencing Student Outcomes and School Effectiveness Using Hierarchical Linear Models. Doctoral Thesis (Curriculum Research and Development), Graduate School, Srinakharinwirot University. Prasarnmit Campus.

[7] Meltem Koçak, Yasin Soylu (2017). Analysis of Pre-service Mathematics Teachers' Teaching Strategy Knowledge of Geometric Formulas. Universal Journal of Educational Research, 5(3), 297 - 315. DOI: 10.13189/ujer.2017.050302.

[8] TIMSS. (2017). User guide for the International database. Publisher: TIMSS \& PIRLS International Study Center. Lynch School of Education, Boston College.

[9] Sirichai Kanchanawasi. (2005). Classical Test Theory. The 5th edition. Bangkok: Chulalongkorn University Printing 
House.

[10] Sirichai Kanchanawasi. (2007). Modern Test Theories. The 3rd edition. Bangkok: Chulalongkorn University Printing House.

[11] Cheong, Y. F. (2006). Analysis of school context effects on differential item functioning using hierarchical generalized linear models. International Journal of Testing 6(1): 57-79.

[12] Chiu, M.M., Xihua, Z. (2008). Family and motivation effect on mathematics achievement: Analyses of students in 41 countries. Learning and Instruction 18: 321-336.

[13] Duduzile Rosemary Mkhize (2017). Forming Positive Identities to Enhance Mathematics Learning among Adolescents. Universal Journal of Educational Research, 5(2), 175 - 180. DOI: 10.13189/ujer.2017.050201.

[14] Nittaya Muadthaisong (2000). Casual Mediation of Student, Teacher and School Factors Affecting Mathematics Achievement: A Meta-Analysis of Research. Master Thesis (Educational Research), Faculty of Education, Chulalongkorn University. 